\title{
Correction to: Does CEO (over)compensation influence corporate reputation?
}

\section{Ann-Christine Schulz ${ }^{1} \cdot$ Miriam Flickinger $^{2}$ D}

Published online: 7 January 2019

(c) Springer-Verlag GmbH Germany, part of Springer Nature 2019

\section{Correction to: Review of Managerial Science https://doi.org/10.1007/s11846-018-0305-0}

In Table 2, the complete details of "column of Model 2, Model 2a, Model 2b, Model $2 c$ " were inadvertently omitted, while structuring the table. Hence, the original version of this article contained an incomplete table. The complete Table 2 and its reference should read as follows:

The original article can be found online at https://doi.org/10.1007/s11846-018-0305-0.

Miriam Flickinger

mflickinger@mgmt.au.dk

Ann-Christine Schulz

ann.schulz@fh-wien.ac.at

1 University of Applied Sciences for Management and Communication (FH Wien der WKW), Waehringer Guertel 97, 1180 Vienna, Austria

2 Department of Management, Aarhus University, Fuglesangs Allé 4, 8210 Aarhus V, Denmark 


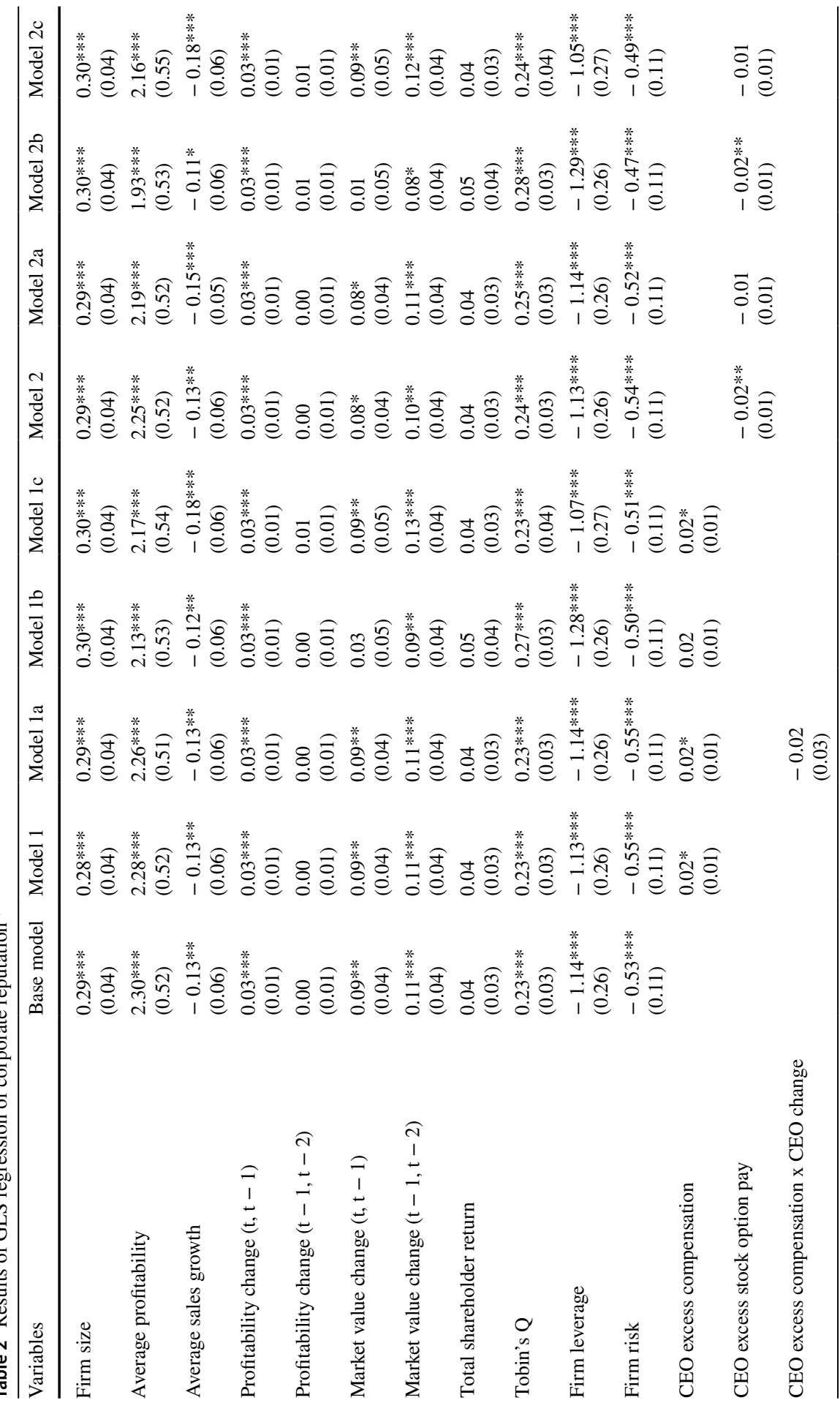




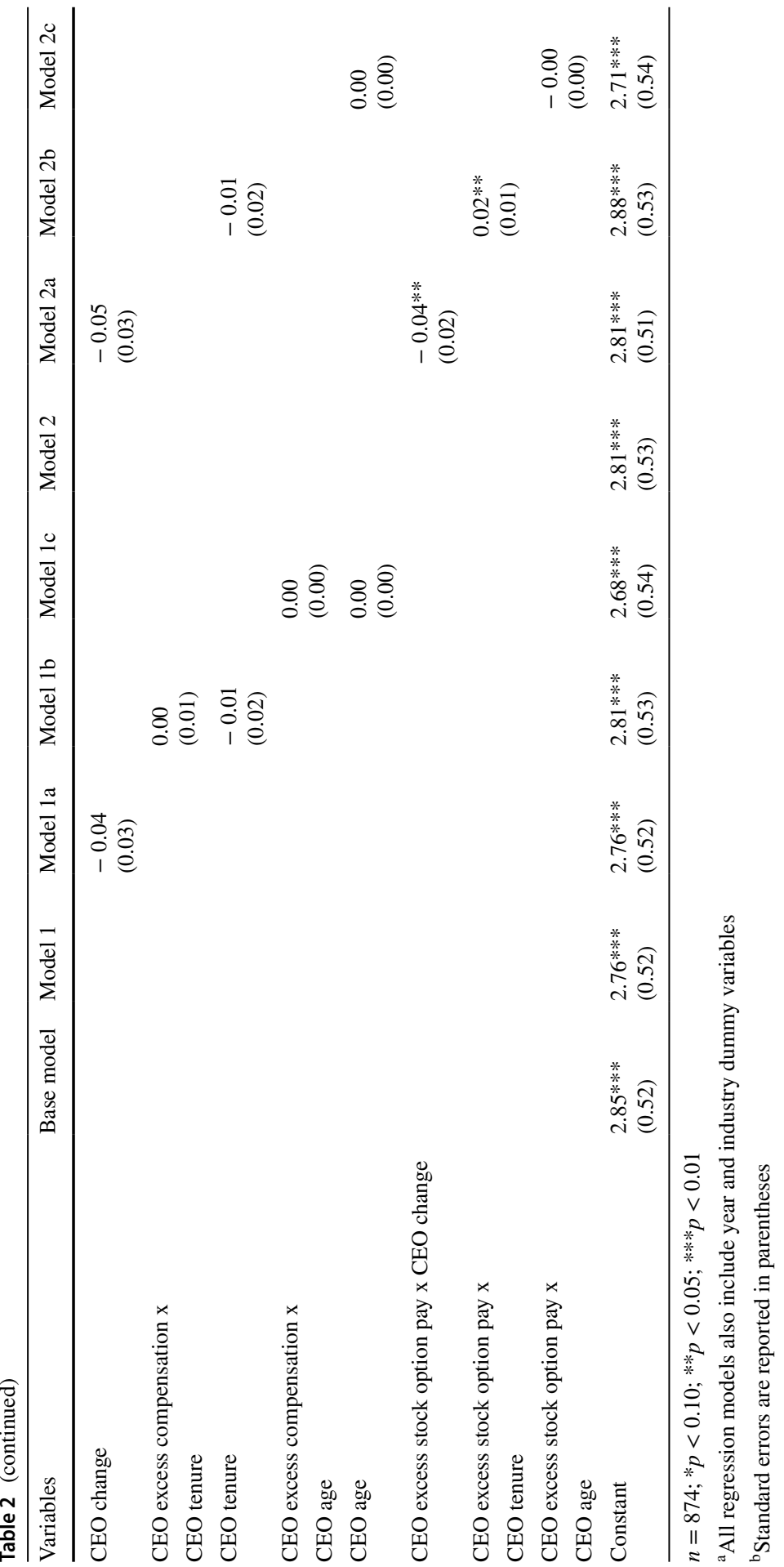




\section{Reference}

Schulz AC, Flickinger M (2018) Does CEO (over)compensation influence corporate reputation? Rev Manag Sci. https://doi.org/10.1007/s11846-018-0305-0 